CORRECTION

https://doi.org/10.1038/s41586-018-0370-1

\title{
Publisher Correction: Parasitic helminths induce fetal-like reversion in the intestinal stem cell niche
}

Ysbrand M. Nusse, Adam K. Savage, Pauline Marangoni, Axel K. M. Rosendahl-Huber, Tyler A. Landman,

Frederic J. de Sauvage, Richard M. Locksley \& Ophir D. Klein

Correction to: Nature https://doi.org/10.1038/s41586-018-0257-1, published online 27 June 2018.

In this Letter, the received date was erroneously written as 13 April 2018, instead of 23 March 2017. Authors R.M.L. and O.D.K. were incorrectly denoted as 'equally contributing' authors. In Extended Data Fig. 4g, the black and white labels for 'control' and 'IFN $\gamma$ ' were reversed. These errors have all been corrected online. 